\title{
nature
}

\section{Do we still need astronauts?}

Sending people into space for science is questionable and expensive. But a new proposed location for space telescopes, and the inevitable maintenance missions they will require, could provide a boost for the astronaut programme.

W hen humans first ventured into space in the 1960s, many people saw it as the opening of a new chapter of history, the beginning of a long, inevitable migration upwards and outwards. It hasn't worked out that way. In fact, it sometimes seems that the astronaut programme is merely playing out that initial burst of energy and is now in freefall, like a spent rocket arcing back to Earth.

One need look no further than the International Space Station, the centrepiece of NASA's human spaceflight programme, for evidence of inertia. Eighteen years and more than US $\$ 20$ billion into the project, it still has no agreed purpose. Economic justifications better manufacturing processes, biotechnology breakthroughs, and so on - have been discredited. The most compelling remaining reason to send astronauts into space is to develop engineering skills and conduct biomedical studies that allow us to send more astronauts into space - a circular and ultimately hollow argument unless we really do intend to leave Earth's orbit again someday.

Do we? Mars has long been viewed as the next destination, but that planet is 200 times farther away than the Moon, and will be difficult and expensive for humans to reach. With no Apollo-style race to win, NASA appears to be in no hurry to send astronauts there, and has only robots in mind for Mars exploration in the foreseeable future.

Into this generally gloomy picture comes a new idea, and a new destination. A million miles from Earth is the L2 lagrangian (or libration) point, an ideal place to station telescopes as the combined gravitation of Earth and the Sun would fix them in place (see News Feature, page 666). At least eight new space observatories are planned to take up residence there by 2020 . The question is whether astronauts will also make the trip, to repair and upgrade the telescopes.

For advocates of human spaceflight, L2 is an appealing short-term destination, more adventurous than Earth's orbit but not as daunting as Mars. Like the missions to service the Hubble Space Telescope, it would stretch astronauts' skills, but not to breaking point. It seems possible, maybe even affordable.

But if we are to evaluate honestly whether astronauts are necessary for maintaining L2 telescopes, we have to ask whether robots could do the job just as well. To be fair, we should look well beyond today's capabilities. Outfitting astronauts for a million-mile journey, or even for the shorter trip to the vicinity of the Moon, as proposed by a team of NASA forward-thinkers, will cost billions and take at least a decade. If you gave the world's leading roboticists ten years and those same billions, what might they come up with? Only by running that experiment can we truly decide whether scientists need astronauts to build and service future space observatories.

If it turns out that they don't, we should look for other reasons to continue sending astronauts into space. Because people are risking their lives, and because human spaceflight is still fantastically expensive, one hopes for a deeper and more serious purpose than nostalgia (veteran astronaut John Glenn's 1995 shuttle flight was the most watched mission of the 1990s) or show business (reporters asked pop star and wannabe cosmonaut Lance Bass more questions than any of the professional astronauts at a recent NASA press conference).

For many people, space exploration touches a deep emotional nerve, and needs no further justification. Asked why he wanted to climb Everest, George Mallory famously replied, "Because it's there." Depending on your point of view, that rationale is either hopelessly glib, or the only truthful answer. And without a clear, practical job for astronauts to do in space — such as servicing telescopes — NASA will probably always be caught between those two viewpoints.

\section{Towards a European Research Council}

\section{A meeting last week showed that Europe's science ministers should now focus on the bigger picture.}

$\Lambda$ bottom-up swell of lobbying from researchers in favour of the formation of a European Research Council (ERC) is about as likely as a thunderclap on the Moon. Only science-policy wonks are likely to have followed in detail the public discussion of the idea (see Nature 419, 108-109; 2002 and 419, 249-250; 2002). A correspondent on the topic (Nature 419, 248; 2002) was sceptical about whether Europe is ready - such a funding agency would, it was argued, be bureaucratic and inevitably seek to take funds from existing bodies, which have themselves failed to foster international competitiveness.

Scepticism is understandable given the track record of some national agencies and of debates at the European level. On the other hand, centres such as the European laboratory for particle physics (CERN) and the European Molecular Biology Laboratory are comparatively efficient and have struck a balance between scientific independence and financial accountability. And they produce great science.

These examples may inspire, but a drive from the top down is now required if the idea of a pan-European funding agency, with fundamental research as its top priority and free to fund according to merit, is to succeed. A meeting last week of stakeholders, including representatives of national funding agencies, was a good start. Organized in Copenhagen under the Danish presidency of the European Union, it achieved a strong degree of consensus that an ERC is indeed necessary, despite notable scepticism from the UKMedical Research Council and the CNRS, France's main basic research agency.

We can now hope for practical leadership, especially from Germany, the Netherlands and Scandinavia. The organization of heads of European national research councils (Eurohorcs) is likely to launch a scheme of young investigators' awards in which these and other countries will take a lead. And the European Commission's Sixth Framework Programme is set to boost the European Science Foundation's Eurocores collaboration scheme by 20 million euros (US\$19.7 million).

Given such positive signs, and the expressed aims of government heads to boost funds for European science, it would be appropriate for research ministers to establish a new goal: the formation by 2007 of an independent ERC, charged only with funding the best research, with an annual budget in excess of 5 billion euros. 